\title{
Risk Factors for Early and Late Onset Preeclampsia in Women without Pathological History: Confirmation of the Paramount Effect of Excessive Maternal Pre-Pregnancy Corpulence on Risk for Late Onset Preeclampsia
}

\author{
Pierre-Yves Robillard MD ${ }^{1,2 *}$
}

1Service de Néonatologie. Centre Hospitalier Universitaire Sud Réunion, BP 350, 97448 Saint-Pierre Cedex, La Réunion, France

${ }^{2}$ Centre d'Etudes Périnatales Océan Indien (CEPOI). Centre Hospitalier Universitaire Sud Réunion, BP 350, 97448 Saint-Pierre cedex, La Réunion, France

${ }^{*}$ Corresponding author: Dr Pierre-Yves Robillard. Service de Néonatologie. Centre Hospitalier Universitaire Sud Reunion, BP 350, 97448 Saint-Pierre cedex, France; Tel: \#\#(262) 2623591 49; Fax: \#\#(262) 2623592 93; E-mail: robillard.reunion@wanadoo.fr; pierre-yves.robillard@chu-reunion.fr

Received: October 13, 2020; Accepted: November 04, 2020; Published: November 06, 2020

\begin{abstract}
Objectives: Several major risk factors for preeclampsia being internationally consensual, we investigated risk factors for EOP and LOP in a "knock-out $(\mathrm{KO})$ population" where we excluded 8 risks factors: all women with multiple pregnancies, pre-existing diabetes mellitus, chronic hypertension, history of previous preeclampsia, "coagulopathies", renal or thyroid diseases and smokers.

Study design: South-Reunion University's maternity (Reunion Island, Indian Ocean). 19 year-observational population-based cohort study (20012019). Epidemiological perinatal data base with information on obstetrical and neonatal risk factors. All consecutive singleton pregnancies (>21 weeks) compared with all preeclamptic pregnancies delivered in the south of Reunion island.
\end{abstract}

Main outcome measures: Comparing crude risk factors between EOP and LOP, and logistic regression model between EOP and LOP women with the general "KO population".

Results: The 56,570 women belonging to the "knock-out population" comprised 72\% of all women having delivered singleton babies during the 19- year survey and $63 \%$ of all preeclamptic cases. In this "virgin population", we over-confirm that overweight and different classes of obesities are linearly and increasingly linked with only LOP, and completely disconnected with EOP. For EOP, this KO population revealed that history of previous perinatal death (mainly intra-uterine fetal deaths) have a tendency to be an independent factor (aOR 1.69, $\mathrm{p}=0.07)$. "New paternity" was an independent factor for both EOP and LOP (aOR 3.5 for EOP, $\mathrm{p}=0.006$, and aOR 4.3, $\mathrm{p}<0.0001$ for LOP).

Conclusion: Besides the indications of aspirin prevention as soon as the $16^{\text {th }}$ week of gestation to prevent EOP (some $60 \%$ possible decreased risk), new paternity could be further investigated. Concerning the LOP risk, maternal pre-pregnancy high BMIs should be monitored through adequate gestational weight gains since the first prenatal visit to lower the incidence of LOP possibly by $30-40 \%$.

Keywords: Preeclampsia, Epidemiology, Early onset preeclampsia, Late onset preeclampsia, Gestational weight gain

\section{Introduction}

This is the fourth study of a tetralogy on our population-based preeclamptic singleton cohort in Reunion island (Ocean Indian, French overseas department). First [1], on this same population we have described that 'Placental preeclampsia' (defective placentation) being linked to early onset preeclampsia (EOP, $<34$ weeks gestation) while 'maternal preeclampsia' (maternal cardiovascular predisposition) being typically manifesting as the late form of the disease LOP is not systematically verified: As a matter of fact: EOP women were older than LOP 29.5 vs. 28.6 years, $\mathrm{p}=0.009$, primigravidas were prone to LOP. History of preeclampsia (aOR 12.8 vs. 7.1), chronic hypertension (aOR 6.5 vs. 4.5) had much higher adjusted odds ratios for EOP than for LOP, $\mathrm{p}<0.001$. Specific to EOP: coagulopathies (see methods for definitions, aOR 2.95, $\mathrm{p}=0.04$ ), stimulated pregnancies (aOR 3.9, $\mathrm{p}=0.02$ ). Specific to LOP: renal diseases (aOR 2.0, $\mathrm{p}=0.05$ ) and protective effect for smoking (aOR. 0.75, $\mathrm{p}=0.008$ ). EOP women were prone to have a lower BMI [1]. This was somehow unexpected that the strongest factors associated with EOP are those concerning multiparas, although preeclampsia is particularly considered as a disease of the first pregnancy [2]. On the other hand, first pregnancies (primigravidity) and younger maternal age (especially $<25$ years) were rather associated with LOP, and not as expected with EOP. These findings (confirming a first study in 2017 [3], with similar results in a 
Pierre-Yves Robillard (2020) Risk Factors for Early and Late Onset Preeclampsia in Women without Pathological History: Confirmation of the Paramount Effect of Excessive Maternal Pre-Pregnancy Corpulence on Risk for Late Onset Preeclampsia

cohort in Madagascar [4]) completely disowned our proposed model in 2007 based on maternal ages [5]: the model we proposed then was that older ages should be more prone to LOP (by a "physiological" looming out of vascular and metabolic predispositions), while at younger ages women should be more prone to EOP (first pregnancies, less vascular and metabolic predispositions at these ages).

Then, and second, we verified if these unexpected results for us were not an effect of a "international bad choice" for the consensual cutoff of 34 weeks to discriminate between EOP and LOP internationally adopted since 2013 [6]. We tested different definitions of EOP-LOP (simulating different cut-offs from 30 weeks gestation to 37 [7]), and fundamental results remained quite identical whatever the cutoff chosen, especially the specific effect of rising maternal ppBMI on LOP [7]. Third, we deepened our analysis [8] and showed that in a multivariate analysis with EOP or LOP as outcome variables compared with controls (normotensive), maternal age and pre-pregnancy BMI were independent risk factors for both EOP and LOP. However, analyzing by increment of 5 (categories of 5 years for the ages, categories of $5 \mathrm{~kg}$ / $\mathrm{m}^{2}$ for $\mathrm{BMI}$ ) rising maternal ages and incidence of preeclampsia were similar for EOP and LOP, while increment of BMI was more specifically associated with LOP [8]. Also, and very important, controlling for maternal ages and booking/pre-pregnancy BMI, gestational diabetes mellitus was no more an independent risk factor neither for EOP nor for LOP. Further, smoking during pregnancy was protective only on LOP (30\% decrease) and not on EOP [8].

After these three studies $[1,7,8]$, we noticed that women with the 8 major well-known risk factors for preeclampsia that we confirmed (multiple pregnancies, chronic hypertension, diabetes, smoking, renal and thyroid diseases, "coagulopathies" and multiparous having a previous history of preeclampsia) represented indeed only $28 \%$ of our parturients. What about the other $72 \%$ ? Therefore, we sought to explore what are the risk factors for EOP and LOP in women "without morbidities and past" (after excluding the 8 major risk factors). This is the purpose of the present study.

\section{Materials and Methods}

From January $1^{\text {st }}, 2001$, to June 30,2019 , the hospital records of all women delivered at the maternity of the University South Reunion Island (ap. 4300 births per year) were abstracted in standardized fashion. The study sample was drawn from the hospital perinatal database which prospectively records data of all mother-infant pairs since 2001 . Information is collected at the time of delivery and at the infant hospital discharge and regularly audited by appropriately trained staff. These epidemiological perinatal data base which contained information on obstetrical risk factors, description of deliveries and neonatal outcomes. For the purpose of this study records have been validated and have been used anonymously. As participants in the French national health care system, all pregnant women in Reunion Island have their prenatal visits, biological and ultasonographic examinations, and anthropological characteristics recorded in their maternity booklet.

Preeclampsia, gestational hypertension and eclampsia were diagnosed according to the definition issued by the International Society for the Study of Hypertension in Pregnancy (ISSHP) relatively to the guidelines in force at the year of pregnancy.

\section{Design and Study Population}

The maternity department of Saint Pierre hospital is a tertiary care centre that performs about 4300 deliveries per year, thus representing about $80 \%$ of deliveries of the Southern area of Reunion Island, but is the only level 3 maternity (the other maternity is a private clinic, level 1 which is not allowed to follow/deliver preeclamptic pregnancies). Reunion Island is a French overseas region in the Southern Indian Ocean. The entire pregnant population has virtually access to maternity care. This is provided free of charge by the French healthcare system, which combines freedom of medical practice with nationwide social security.

\section{Definition of Exposure and Outcomes}

Renal diseases were defined as patients with known pre-existing nephropathies (glomerulopathies, tubulopathies, renal failure, diabetic nephropathies) and urological pathologies were excluded. Thyroid diseases were defined as hypo/hyperthyroidy, goitre, thyroiditis, thyroidectomy. Coagulopathies were defined as antiphospholipid syndrome, protein $\mathrm{C}$ /protein $\mathrm{S}$ deficit, factor 5 Leyden or other coagulation factors deficits at any time they were reported in the records (they were not systematically screened in all women as in a case-control study).

Preeclampsia was defined according to the World Health Organization recommendations [9-11] and the International Society for the study of Hypertension in Pregnancy [12] as the new onset of hypertension ( $\mathrm{BP} \geq 140 \mathrm{mmHg}$ systolic or $\geq 90 \mathrm{~mm} \mathrm{Hg}$ diastolic) at or after 20 weeks' gestation and substantial proteinuria ( $>0.3 \mathrm{~g} / 24$ hours). Early onset preeclampsia was defined as preeclampsia that developed before 34 weeks of gestation.

The "primipaternity" item (changing father for the index pregnancy) has been added in the database in 2018 and has been prospectively recorded since then. It is the sum of all primigravidas (and not primiparas) plus multiparous having changed partner for the index pregnancy. For the other years (2001-2017), we retrospectively looked at all free commentaries (possible in each record) for "changing father, changing paternity, new father, new partner etc...." (therefore probably non-exhaustive), but we retrieved hundreds of cases $(\mathrm{N}=552)$.

\section{Statistical Analysis}

Data is presented as numbers and proportions (\%) for categorical variables and as mean and standard deviation (SD) for continuous ones. Comparisons between groups were performed by using $\chi^{2}$-test; odds ratio (OR) with $95 \%$ confidence interval (CI) was also calculated. Paired t-test was used for parametric and the Mann-Whitney $U$ test for non-parametric continuous variables. P-values $<0.05$ were considered statistically significant. Epidemiological data have been recorded and analysed with the software EPI-INFO 7.1.5 (2008, CDC Atlanta, OMS), EPIDATA 3.0 and EPIDATA Analysis V2.2.2.183. Denmark.

Further, to validate the independent association of maternal prepregnancy BMI, or maternal ages and other confounding factors on EOP or LOP we realized a multiple regression logistic model. Variables associated with in bivariate analysis, with a p-value below 0.1 or known to be associated with the outcome in the literature were included in the model. A stepwise backward strategy was then applied to obtain 
Pierre-Yves Robillard (2020) Risk Factors for Early and Late Onset Preeclampsia in Women without Pathological History: Confirmation of the Paramount Effect of Excessive Maternal Pre-Pregnancy Corpulence on Risk for Late Onset Preeclampsia

the final model. The goodness of fit was assessed using the HosmerLemeshow test. A p-value below 0.05 was considered significant. All analyses were performed using MedCalc software (version 12.3.0; MedCalc Software's, Ostend, Belgium).

\section{Results}

During this 19 year period ( $1^{\text {st }}$ January 2001-31 $1^{\text {st }}$ of December 2019), there were 2007 preeclamptic women (PE) in the south of the island of Reunion, of which 115 multiple pregnancies. Out of 76,591 singleton pregnancies, the baseline population consisted of 1,892 singleton preeclamptic pregnancies, incidence $2.5 \%$ (614 EOP and 1,278 LOP).
For the purpose of the present study, we excluded from all our database 1) multiple pregnancies 2) chronic hypertension 3) diabetic women 4) smokers 5) renal diseases 6) thyroid diseases 7) "coagulopathies" (see methods) and 8) multiparous having a previous history of preeclampsia. What we propose to call the "knock-out (KO)" population.

The KO population (preeclamptics and controls) became 1,198 preeclamptics $/ 56,570$ singleton pregnancies (incidence $2.1 \%$ ). The KO population represents then $72 \%$ of all parturients and $63 \%$ of all preeclamptics.

We tested first in Table 1 crude risk factors' comparisons between women presenting EOP or LOP (Odds ratios being EOP vs. LOP).

Table 1: Crude differences between EOP and LOP. In bold, crude results in the entire 19-year cohort $(\mathrm{N}=76,0000)$, already detailed in preceding studies [1,7]. In italic, crude results in the "knock-out" population $(\mathrm{N}=56,570)$.

\begin{tabular}{|c|c|c|c|}
\hline $\begin{array}{l}\text { Non significant results } \\
\text { Left numbers EOP } \mathrm{N}=\mathbf{6 6 2} \text {, } \text { knock-out } K O N=378 \\
\text { Right numbers LOP } \mathrm{N}=\mathbf{1 3 4 5} \text {, } \text { knock-out } K O N=820\end{array}$ & P value & $\begin{array}{l}\text { Significant results } \\
\text { EOP vs. LOP } \\
\text { ODDS ratios } \\
{[95 \% \mathrm{CI}]}\end{array}$ & P value \\
\hline $\begin{array}{cl}\text { Gestity (mean, SD) } & \mathbf{2 . 9 1} \text { vs. } \mathbf{2 . 7 3} \\
K O & 2.49 \text { vs. } 2.31\end{array}$ & $\begin{array}{l}0.10 \\
0.10\end{array}$ & $\begin{array}{|cc|}\text { Mother Age (years, SD) } & 29.5 \text { vs. } 28.6 \\
K O & 28.2 \text { vs. } 26.9\end{array}$ & $\begin{array}{l}0.009 \\
0.002\end{array}$ \\
\hline $\begin{array}{l}\text { Parity (mean, SD } \\
\quad K O\end{array}$ & $\begin{array}{l}0.25 \\
0.37\end{array}$ & \begin{tabular}{|rcc|}
\multicolumn{2}{l|}{ Primigravidity } \\
& $\mathbf{3 1 . 5 \%}$ vs. $\mathbf{3 7 . 2} \%$ & OR= $\mathbf{0 . 7 8}[\mathbf{0 . 6 3 - 0 . 9 6}]$ \\
KO & $40.1 \%$ vs. $46.2 \%$ & $0.78[0.61-1.0]$
\end{tabular} & $\begin{array}{l}0.02 \\
0.05\end{array}$ \\
\hline & & $\begin{array}{|ccc|}\text { Primiparity } & \mathbf{4 5 . 8 \%} \text { vs. } \mathbf{4 9 . 7 \%} & \text { OR } \mathbf{0 . 8 5}[\mathbf{0 . 7 0 - 1 . 0}] \\
\text { KO } & 56.6 \% \text { vs. } 58.8 \% & \text { OR } 0.91 \\
\end{array}$ & $\begin{array}{l}0.05 \\
0.24\end{array}$ \\
\hline $\begin{array}{ccc}\text { Adolescents }(<\mathbf{1 8 y}) & \mathbf{3 . 0 \%} \text { vs. } \mathbf{3 . 4} \% & \text { OR } \mathbf{0 . 8 9} \\
K O & 4.3 \% \text { vs. } 4.8 \% & \text { OR } 0.88\end{array}$ & $\begin{array}{l}0.67 \\
0.68\end{array}$ & 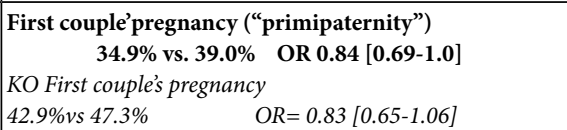 & $\begin{array}{l}0.04 \\
0.07\end{array}$ \\
\hline $\begin{array}{ccc}35 \text { years }+ & \mathbf{2 5 . 8} \text { vs. } \mathbf{2 3 . 8} \% & \text { OR }=\mathbf{1 . 1 0} \\
K O & 19.8 \% \text { vs. } 16.1 \% & O R=1.28\end{array}$ & $\begin{array}{l}0.39 \\
0.12\end{array}$ & $\begin{array}{|cr|}\text { Pre-pregnancy/booking BMI } & \mathbf{2 6 . 4} \text { vs. } 27.1 \mathrm{Kg} / \mathbf{m}^{\mathbf{2}} \\
\mathrm{KO} & 25.42 \mathrm{vs.} 26.0 \mathrm{Kg} / \mathrm{m}^{2}\end{array}$ & 0.06 \\
\hline $\begin{array}{ccc}\text { Grand multiparae }(5+) & \mathbf{1 0 . 8 \%} \text { vs. } \mathbf{9 . 6 \%} & \text { OR }=\mathbf{1 . 1 4} \\
K O & 7.5 \% \text { vs. } 5.7 \% & O R=1.34\end{array}$ & $\begin{array}{l}0.41 \\
0.24\end{array}$ & $\begin{array}{ccc}\text { Atcd perinatal. Deaths } \mathbf{1 2 \%} \text { vs. } \mathbf{7 . 4 \%} & \mathbf{1 . 7 8}[\mathbf{1 . 1}-\mathbf{2 . 6}] \\
K O & 9.5 \% \text { vs. } 4.9 \% & 2.06[1.09-3.9]\end{array}$ & $\begin{array}{l}0.008 \\
0.02\end{array}$ \\
\hline $\begin{array}{ccc}\text { Single } & \mathbf{3 4 . 7 \%} \text { vs. } \mathbf{3 8 . 2} \% \quad \text { OR }=\mathbf{0 . 8 6} \\
\text { KO } & 32.1 \% \text { vs. } 40.8 \% \quad O R=0.69[0.53-0.89]\end{array}$ & $\begin{array}{l}0.14 \\
0.004\end{array}$ & \begin{tabular}{|ccc} 
Stimulated pregnancies & $\mathbf{0 . 8 \%}$ vs. $\mathbf{0 . 2} \%$ & OR $=\mathbf{3 . 4}$ \\
$K O$ & $.1 \%$ vs. $0.4 \%$ & $O R=2.83$
\end{tabular} & $\begin{array}{l}0.07 \\
0.15\end{array}$ \\
\hline $\begin{array}{ccc}\text { Years school } \geq \mathbf{1 0 .} & \mathbf{5 6 . 9 \%} \text { vs. } \mathbf{5 5 . 6} \% & \text { OR }=\mathbf{1 . 0 6} \\
K O & 61.4 \% \text { vs. } 59.7 \% & O R=1.08\end{array}$ & 0.60 & & \\
\hline $\begin{array}{ccc}\mathbf{B M I} \geq \mathbf{2 5} \mathbf{~ k g} / \mathbf{m}^{\mathbf{2}} & \mathbf{5 4 . 5 \%} \text { vs. } \mathbf{5 3 . 7} \% & \text { OR }=\mathbf{1 . 0 3} \\
K O & 46.8 \% \text { vs. } 45.1 \% & O R=1.07\end{array}$ & $\begin{array}{l}0.76 \\
0.60\end{array}$ & & \\
\hline $\begin{array}{ccc}\mathbf{B M I} \geq \mathbf{3 0} \mathbf{~ k g} / \mathbf{m}^{\mathbf{2}} & \mathbf{2 7 . 7 \%} \text { vs. } \mathbf{3 0 . 6 \%} & \mathrm{OR}=\mathbf{0 . 8 7} \\
K O & 22.6 \% \text { vs. } 24.2 \% & O R=0.91\end{array}$ & $\begin{array}{l}0.23 \\
0.57\end{array}$ & & \\
\hline $\begin{array}{ccc}\text { Atcd miscarriage } & \mathbf{3 0 . 9} \% \text { vs. } \mathbf{3 1 . 4} \% & \mathbf{O R}=\mathbf{0 . 9 8} \\
K O & 30.4 \% \text { vs. } 31.1 \% & O R=0.96\end{array}$ & $\begin{array}{l}0.85 \\
0.83\end{array}$ & & \\
\hline $\begin{array}{ccc}\text { Atcd abortion } & \mathbf{2 7 . 0 \%} \text { vs. } \mathbf{2 3 . 3} \% & \text { OR }=\mathbf{1 . 2 2} \\
K O & 30.4 \% \text { vs. } 24.3 \% & O R=1.36\end{array}$ & $\begin{array}{l}0.15 \\
0.09\end{array}$ & & \\
\hline $\begin{array}{ccc}\text { In vitro fecundation } & \mathbf{1 . 3 \%} \text { vs. } \mathbf{1 . 0} \% & \mathbf{O R}=\mathbf{1 . 3 6} \\
K O & 0.8 \% \text { vs. } 0.9 \% & O R=0.90 \\
\end{array}$ & $\begin{array}{l}0.50 \\
0.88\end{array}$ & & \\
\hline \multicolumn{4}{|c|}{ EXCLUDED FROM THIS STUDY POPULATION [results in 1,7] } \\
\hline $\begin{array}{c}\begin{array}{c}\text { Pre-existing diabetes } \quad 3.9 \% \text { vs. } 4 . \% 9 \\
\text { (knock out excluded) }\end{array} \\
\end{array}$ & 0.37 & & \\
\hline 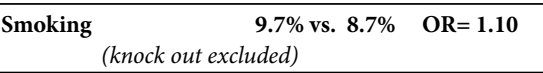 & 0.58 & & \\
\hline 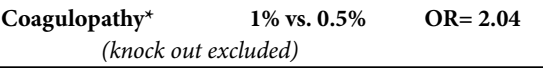 & 0.21 & $\begin{array}{c}\text { Gestational diabetes } 11.9 \% \text { vs. } 17.9 \% 0.68 \text { [0.51-0.90] } \\
\text { (knock out excluded) }\end{array}$ & 0.009 \\
\hline $\begin{array}{c}\text { Atcd thyroid disease\# } \quad 2.5 \% \text { vs. } 1.6 \% \\
\text { (knock out excluded) }\end{array}$ & 0.21 & $\begin{array}{c}\text { Chronic hypertension } 12.7 \% \text { vs. } 9.2 \% \\
\text { (knock out excluded) }\end{array}$ & 0.02 \\
\hline 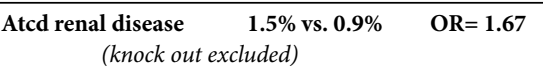 & 0.25 & $\begin{array}{c}\text { Atcd preeclampsia } \quad 18.1 \% \text { vs. } 11.4 \% \\
\text { (knock out excluded) }\end{array}$ & 0.002 \\
\hline
\end{tabular}

\#Goitre, hypo-hyperthyroidy, thyroidectomy, thyroid node, thyroiditis * antiphospholipid syndrome, protein C/protein S deficit, factor 5.

Leyden or other coagulation factors deficits. 
Pierre-Yves Robillard (2020) Risk Factors for Early and Late Onset Preeclampsia in Women without Pathological History: Confirmation of the Paramount Effect of Excessive Maternal Pre-Pregnancy Corpulence on Risk for Late Onset Preeclampsia

In bold are the results of the entire population $(1,892$ singleton preeclamptics/76,591, detailed in preceding studies [1,7]), in italic the same risk factors in women belonging to the KO population. Plus or minus, the comparisons are similar. We have added in the present study the item "primipaternity" which did not existed in the preceding studies $[1,7,8]$. Like primiparity, primipaternity is associated slightly more with LOP than with EOP ( $\mathrm{p}=0.04$ and 0.07$)$. It is of note that women declaring to live single appear in $\mathrm{KO}$ women to be a risk factor rather for LOP (OR 0.69 for EOP, $\mathrm{p}=0.004)$. Therefore, we have included this item in the logistic model.

In Table 2, logistic model, we adopted a different strategy: with the outcomes EOP and LOP, we compared cases and all the general KO population $(n=56,270)$, taking into account the crude results comparing EOP with LOP (Table 1) to choose the selected risk factors . The upper table of the model includes primiparity (therefore also women with possible previous miscarriages or abortions). Below, the lower table includes instead "primipaternity": primigravidas (therefore no possible previous miscarriages or abortions) and multiparas having changed the male partner for the index pregnancy.

First, primiparity and primipaternity are independent factors for both EOP and LOP $(\mathrm{OR} \approx 3 / 4, \mathrm{p}<0.0001)$.

Table 2: Adjusted Odds ratios. "Knockout preeclamptics" vs all women ("knock-out" singleton pregnancies $\mathrm{N}=56,570$ ).

\begin{tabular}{|l|l|l|l|l|}
\hline Primiparity in the model. & $\begin{array}{l}\text { EOP Knockout } \\
\text { aOR }\end{array}$ & P val & $\begin{array}{l}\text { LOP Knockout } \\
\text { OOR }\end{array}$ & P val \\
\hline Age5 (increment 5 years) & $\begin{array}{l}1.046 \\
{[1.02-1.07]}\end{array}$ & 0.002 & $\begin{array}{l}1.042 \\
{[1.02-1.04]}\end{array}$ & 0.001 \\
\hline BMI5 (increment 5kg/m ${ }^{2}$ ) & $\begin{array}{l}1.05 \\
{[1.03-1.07]}\end{array}$ & $<0.0001$ & $\begin{array}{l}1.055 \\
{[1.04-1.07]}\end{array}$ & $<0.0001$ \\
\hline Primiparity & $\begin{array}{l}\mathbf{2 . 9} \\
{[\mathbf{2 . 0 - 4 . 3}]}\end{array}$ & $<\mathbf{0 . 0 0 0 1}$ & $\begin{array}{l}\mathbf{2 . 5 9} \\
{[\mathbf{1 . 9 8 - 3 . 4}]}\end{array}$ & $<\mathbf{0 . 0 0 0 1}$ \\
\hline Atcd abortion & $\begin{array}{l}1.17 \\
{[0.83-1.7]}\end{array}$ & 0.31 & 0.95 & 0.72 \\
\hline Atcd miscarriage & $\begin{array}{l}1.06 \\
{[0.76-1.5]}\end{array}$ & 0.70 & $\begin{array}{l}1.01 \\
{[0.80-1.27]}\end{array}$ & 0.89 \\
\hline Single & 0.85 & 0.33 & 1.05 & 0.64 \\
\hline ART stimulated & $\begin{array}{l}3.6 \\
{[0.87-15.1]}\end{array}$ & 0.07 & 0.82 & 0.85 \\
\hline IVF & 0.96 & 0.97 & 0.90 & 0.86 \\
\hline $\begin{array}{l}\text { Primipaternity\# (instead of } \\
\text { primiparity) in the model }\end{array}$ & $\begin{array}{l}\text { EOP Knockout } \\
\text { aOR }\end{array}$ & $\mathbf{P ~ v a l ~}$ & $\begin{array}{l}\text { LOP Knockout } \\
\text { aOR }\end{array}$ & P val \\
\hline Age5 (increment 5 years) & $\begin{array}{l}1.026 \\
{[1.00-1.05]}\end{array}$ & 0.03 & $\begin{array}{l}1.025 \\
{[1.01-1.04]}\end{array}$ & 0.002 \\
\hline BMI5 (increment 5kg/m ${ }^{2}$ ) & $\begin{array}{l}1.046 \\
{[1.02-1.07]}\end{array}$ & $<0.0001$ & $\begin{array}{l}1.05 \\
{[1.04-1.07]}\end{array}$ & $<0.0001$ \\
\hline Primipaternity\# & $\begin{array}{l}\mathbf{3 . 5} \\
{[\mathbf{1 . 4 - 8 . 6}]}\end{array}$ & $\mathbf{0 . 0 0 6}$ & $\begin{array}{l}\mathbf{4 . 3} \\
{[\mathbf{2 . 4}-7.6]}\end{array}$ & $<\mathbf{0 . 0 0 0 1}$ \\
\hline Atcd abortion & $\begin{array}{l}1.49 \\
{[1.09-2.05]}\end{array}$ & 0.01 & 1.19 & 0.13 \\
\hline Atcd miscarriage & $\begin{array}{l}1.33 \\
{[0.97-1.81]}\end{array}$ & 0.07 & $\begin{array}{l}1.26 \\
{[1.02-1.55]}\end{array}$ & 0.03 \\
\hline Single & 0.88 & 0.44 & 1.11 & 0.27 \\
\hline ART stimulated & $\begin{array}{l}4.7 \\
{[1.15-19.5]}\end{array}$ & 0.03 & 1.06 & 0.95 \\
\hline Atcd perinatal deaths & $\begin{array}{l}1.69 \\
{[0.96-2.99]}\end{array}$ & 0.07 & 1.15 & 0.54 \\
\hline IVF & 0.96 & 0.97 & 0.90 \\
\hline
\end{tabular}

\#Primipaternity : primiparous and multiparous having changed partner for the index pregnancy.
Second, increase of maternal age (by increment of 5 years) is also an independent factor: increase of $4 \%$ per 5 years of age for primiparity and increase of $2 \%$ per 5 years for primipaternity ( both EOP and LOP).

Third, increase of maternal pre-pregnancy BMI (by increments of $\left.5 \mathrm{~kg} / \mathrm{m}^{2}\right)$ : increase of $5 \%$ per $5 \mathrm{~kg} / \mathrm{m}^{2}$ for primiparity and primipaternity ( both EOP and LOP).

Fourth, associated only with EOP: antecedents of perinatal deaths (mainly intrauterine fetal deaths) and medically induced pregnancies by stimulation of ovulation (stronger effect in primipaternity than with primiparity OR 4.7 vs. $3.6, \mathrm{p}=0.03$ ). In vitro fecundations are not associated neither with EOP nor with LOP.

Fifth, history of abortion and miscarriages is not associated with preeclampsia risk in the primiparity model. In the primipaternity model, history of abortions is specifically associated with the risk of EOP. History of miscarriages is slightly associated $(\mathrm{OR} \approx 1.3, \mathrm{p}=0.03)$ with both EOP and LOP.

Figures 1 and 2 show the comparisons between our entire population $(\mathrm{N} \approx 76,591$ singleton pregnancies, already detailed in preceding publications $[1,7])$ and our "knock-out" population $(\mathrm{N} \approx$ $56,570)$.

Figure 1 depicts the effect of increasing maternal ages: in both cases, EOP and LOP increase with maternal ageing.

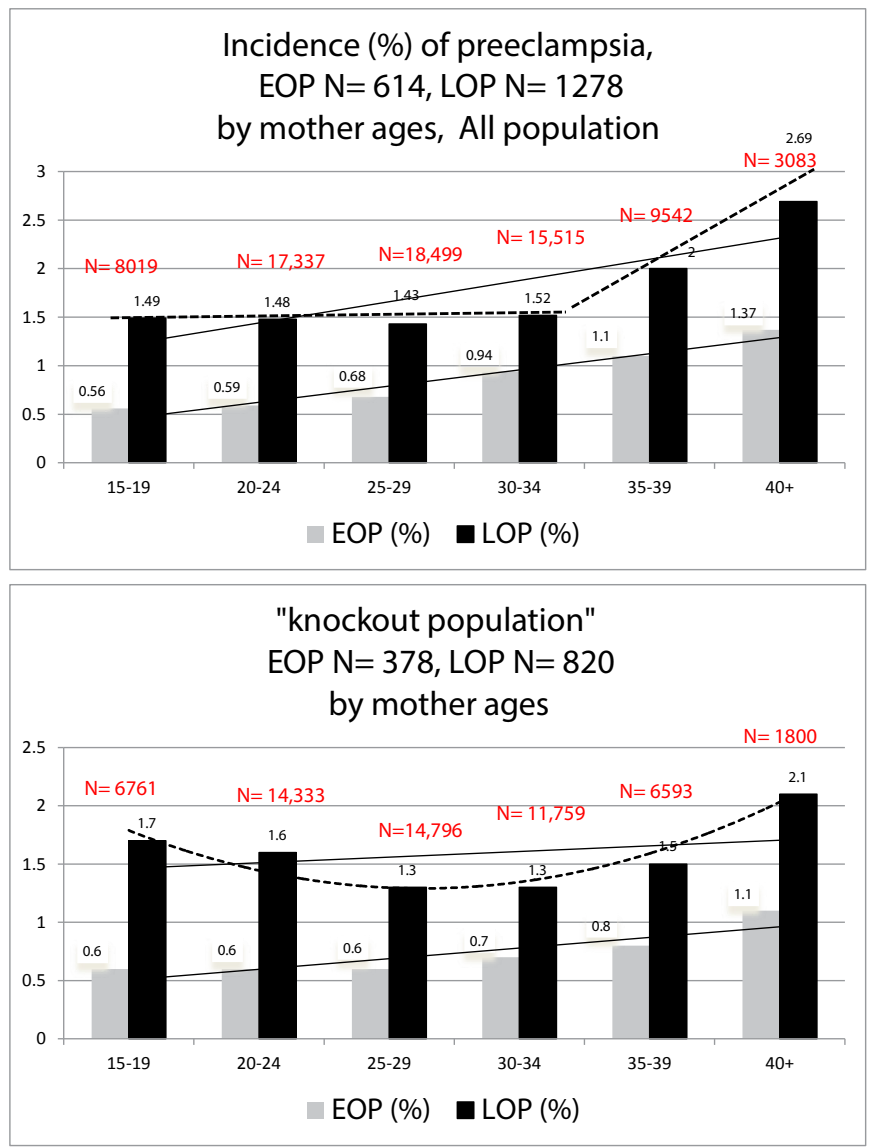

Figure 1: Comparisons of preeclampsia Incidences (\%) by mother ages in 1) all our population 2) in the "knock-out" population. 
Pierre-Yves Robillard (2020) Risk Factors for Early and Late Onset Preeclampsia in Women without Pathological History: Confirmation of the Paramount Effect of Excessive Maternal Pre-Pregnancy Corpulence on Risk for Late Onset Preeclampsia

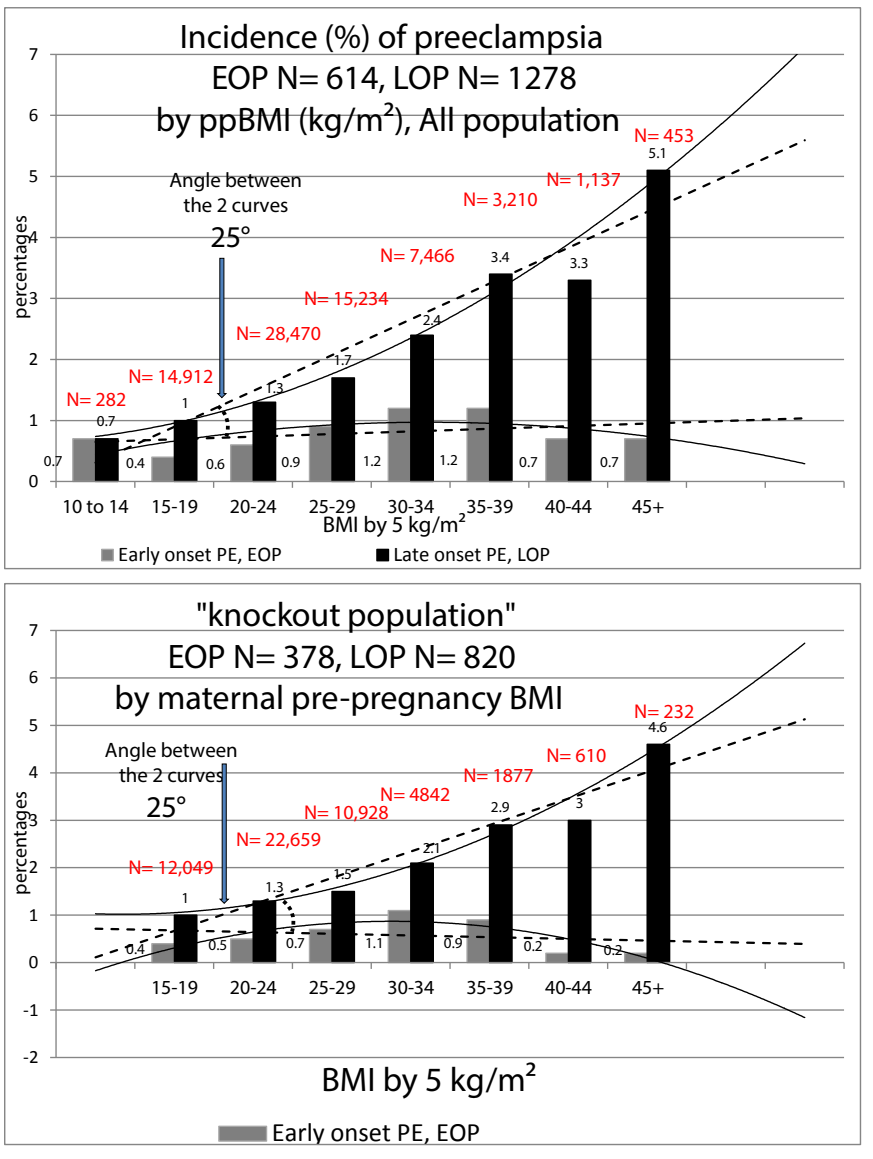

Figure 2: Comparisons of preeclampsia Incidences (\%) by maternal pre-pregnancy Body Mass Index (BMI) in 1) all our population 2) in the "knock-out" population.

Figure 2 depicts the effect of increasing maternal pre-pregnancy BMI: in the KO population (women without past and morbidities) the paramount effect of increase of BMI is specific with the increase of only LOP. In the KO population, the ppBMI has a nil effect on the occurrence of EOP (stronger effect than in the entire population).

\section{Discussion}

First of all, "women without morbidities and past" (multiple pregnancies, chronic hypertension, diabetes, smoking, renal and thyroid diseases, "coagulopathies" and multiparous having a previous history of preeclampsia, or "knock-out population", KO) comprise $72 \%$ of a female reproductive community. It is also of note that they also comprise $63 \%$ of all preclampsia cases (PE incidence of $2.1 \%$ vs. $2.5 \%$ in the general population).

Second, Late Onset Preeclampsia (LOP): this study on a "pure population" confirms the paramount effect of increased prepregnancy BMI targeted mainly on late onset preeclampsia $(\geq 34$ weeks gestation) that we had already previously described [8]. In KO women "without past and morbidities", the effect is absolutely stronger than in our entire population (see comparisons in Figure 2). The BMI increase has a very poor effect on the early onset (EOP) form. Obesity is a well-known risk factor for late-onset preeclampsia [9], but this effect varies within different classes of obesities (ClassI to III) [8]. Very recently Bicocca, Sibai et al. [10] also thought to have a look at these 3 classes of obesity in a large cohort in the USA and noticed also that rising classes of obesities are significantly and linearly associated with the risk of hypertensive disorders of pregnancy (HDP). They found that the slope for EOP was different than with LOP (with an angle of $16^{\circ}$ ). We have found in 2019 similar results in a preeclamptic population-based in Reunion island, but our association was quite only associated with LOP and poorly with EOP, and our slopes made an angle of $25^{\circ}$ [8], see also Table 2. However, there were two major methodological differences with Bicocca et al. and our study [8]: we took only preeclamptic women (and not all HDP), and used the PREPREGNANCY BMI, which is then predictive before any pregnancy, Bicocca et al. used maternal BMI AT DELIVERY which includes then the gestational weight gain (GWG). As a matter of fact, GWG is different if you deliver at 29 or at 38 weeks, and GWG comprises also edemas.

This specific association between maternal pre-pregnancy corpulence and LOP is not a detail, as LOP is by far the predominant form of preeclampsia ( $90 \%$ in literature from developed countries, some $70 \%$ in the rest of the world [11]). This confirmation is the major findings of this "knock-out" epidemiological study and, there, we might have an immediate leverage of action (prevention) very soon $[12,13]$.

Third, concerning Early Onset Preeclampsia (EOP), this study made on a "virgin-risk population" may reveal some tracks. Besides a predictive screening by what we may call the "Nicolaides-Poon's algorithms" [14-17], some clinical items may be added to the EOP risk: the involvement of a new male partner for the index pregnancy and history of previous perinatal death (mainly intra-uterine fetal deaths).

\section{A) Primipaternity and History of Abortions and Miscarriages in Multigravidas}

In this study, we have indirect approach of a male partner involvement, and, interestingly rather a risk for EOP (therefore a possible target for aspirin prevention?). First of all, history of abortions or miscarriages in multiparas were not associated with any preeclampsia risk in the general population (Table 1 , bold results), and in our logistic model including primiparity (Table 2, upper Table) and in the results of preceding studies on this same population [1]. In the present study of a KO population, crude results (Table 1 , italic results) and in the primipaternity model (Table 2, lower Table), history of abortions is specifically associated with the risk of EOP, and miscarriages equally between EOP and LOP. At first, the wellknown effect of primiparity (cornerstone of all epidemiological studies on preeclampsia) is also confirmed in primipaternity (Table 2). For primipaternity, we may assume that women having changed male partner for the index pregnancy may have had preceding abortions with different partner(s) [18].

\section{B) Primipaternity and Medically Induced Pregnancies}

It is of note (Table 2) that in vitro-fecundations (including ICSI) are not independently associated with any kind of preeclampsia risk (EOP \& LOP) in primiparas and 
Pierre-Yves Robillard (2020) Risk Factors for Early and Late Onset Preeclampsia in Women without Pathological History: Confirmation of the Paramount Effect of Excessive Maternal Pre-Pregnancy Corpulence on Risk for Late Onset Preeclampsia

"primipaternity-multiparas", Table 2. In our ART centre in Reunion, $88 \%$ of our IVF are made with the habitual male partner of the couple, with very few oocyte donations $(\mathrm{N}=31$ in 19 years) and very few with unknown donor sperm. Contrary to IVF, in our experience, medically induced pregnancies by stimulation of ovulation were a strong independent factor specifically associated with EOP. We have verified and $2 / 3$ $(66.6 \%)$ of our stimulated pregnancies were primiparas, and $48 \%$ primigravidas. Antecedents of abortions as risk factors specific to EOP in women having a new partner suggest the "male effect" as possible etiology of preeclampsia, and more specifically in this study for EOP [19-22].

\section{C) Antecedents of Perinatal Deaths}

Controlling for primipaternity (Table 2, lower Table), previous perinatal deaths have a tendency to be an independent factor for the EOP risk, $\mathrm{p}=0.07$ (NB: not associated with previous history of preeclampsia, as these women have been removed from the study population).

The Centre Hospitalier Universitaire Sud-Reunion's maternity (Level 3, European standards of care) is the only public hospital in the southern part of Reunion Island (Indian Ocean, French overseas department). It serves the whole population of the area (ap. 360,000 inhabitants, and 5,100 births per year). With 4,300 births per year, the university maternity represents $82 \%$ of all births in the south of the island. But, as a level 3 (the other maternity is a private clinic, level 1), we are sure all the preeclampsia cases were referred to our hospital during the 19-year period. This is therefore a real population-based study. As a limitation of the study, we have to consider the retrospective nature of the study that, although the number of information that is recorded, some characteristics may miss like length of sexual relationship and/ or primipaternity. The "primipaternity" item, being quoted mainly retrospectively for the period 2001-2017, is not completely reliable. "Coagulopathies" were not systematically screened in all women (cases and controls). However, every time that a woman was known to have one of these characteristics, they were scrupulously included in the database. The strengths of this study are mostly related to the homogeneity of data in such a large cohort as they were collected in a single center (no intercenter variability) and not based on national birth registers but directly from medical records (avoiding inadequate codes).

\section{Conclusion}

This study made on a population exempt from the eight internationally consensual major risk factors for preeclampsia may be of some interest. 1) for late onset preeclampsia LOP: it confirms the specific association between high maternal BMI and the immense burden of late-onset preeclampsia (LOP) [8]. This is of major importance in a planet where the overweight-obesity problem is constantly rising. Here, there is a reasonable hope to have a positive intervention by a monitored management of gestational weight gain since the beginning of any pregnancy allowing to lower the LOP incidence by some $30-40 \%[12,13]$. 2) For early onset preeclampsia EOP (here we may expect a $60 \%$ decrease by aspirin prevention
$[14,15])$, this KO population revealed underlying risk factors: history of preceding perinatal deaths (intra-uterine fetal deaths) and arguments for "new paternity". International efforts should be focused on asking to all first-couple's pregnancies (primiparas and multiparas having changed the male partner) the length of cohabitation before conception. A sexual cohabitation of less than 6 months could be a risk factor for EOP and, if confirmed, beneficiate of early aspirin prevention since the $16^{\text {th }}$ week of gestation [14-17].

\section{References}

1. Robillard PY, Dekker G, Scioscia M, Bonsante F, Iacobelli S, et al. (2020) The blurring boundaries between placental and maternal preeclampsia: a critical appraisal of 1800 consecutive preeclamptic cases. J Matern Fetal Neonatal Med 6: 1-7. [crossref]

2. Burton GJ, Redman CW, Roberts JM, Moffett A (2019) Pre-eclampsia: pathophysiology and clinical implications. BMJ 366: 2381. [crossref]

3. Iacobelli S(1), Bonsante F(2), Robillard PY(2) (2017) Comparison of risk factors and perinatal outcomes in early onset and late onset preeclampsia: A cohort based study in Reunion Island. J Reprod Immunol 123: 12-16. [crossref]

4. Ratsiatosika AT, Razafimanantsoa E, Andriantoky VB, Ravoavison N, Andrianampanalinarivo Hery R, et al. (2019) Incidence and natural history of preeclampsia/eclampsia at the university maternity of Antananarivo, Madagascar: high prevalence of the early-onset condition. J Matern Fetal Neonatal Med 32: 32663271. [crossref]

5. Robillard PY, Dekker G, Chaouat G, Hulsey TC (2007) Etiology of preeclampsia: maternal vascular predisposition and couple disease--mutual exclusion or complementarity? J Reprod Immunol 76: 1-7. [crossref]

6. Tranquilli AL, Brown MA, Zeeman GG, Dekker G, Sibai BM (2013) The definition of severe and early-onset preeclampsia. Statements from the International Society for the Study of Hypertension in Pregnancy (ISSHP). Pregnancy Hypertens 3: 44-77. [crossref]

7. Robillard PY, Dekker G, Scioscia M, Bonsante F, Iacobelli S, et al. (2020) Validation of the 34-week gestation as definition of late onset preeclampsia:Testing different cutoffs from 30 to 37 weeks on a population-based cohort of 1700 preeclamptics. Acta Obstet Gynecol Scand.

8. Robillard PY, Dekker G, Scioscia M, Bonsante F, Iacobelli S, et al. (2019) Increased BMI has a linear association with late-onset preeclampsia: a population-based study. PLoS One 14: 0223888. [crossref]

9. Lisonkova S, Joseph KS (2013) Incidence of preeclampsia: risk factors and outcomes associated with early-versus late-onset disease. Am J Obstet Gynecol 209: 544. [crossref]

10. Bicocca MJ, Mendez-Figueroa H, Chauhan SP, Sibai BM (2020) Maternal Obesity and the Risk of Early-Onset and Late-Onset Hypertensive Disorders of Pregnancy. Obstet Gynecol 136: 118-127. [crossref]

11. Robillard PY, Dekker G, Chaouat G, Elliot MG, Scioscia M (2019) High incidence of early onset preeclampsia is probably the rule and not the exception worldwide 20th anniversary of the reunion workshop. A summary. J Reprod Immunol 133: 30-36.

12. Robillard PY, Dekker G, Boukerrou M, Boumahni B, Hulsey T, et al. (2020) Gestational weight gain and rate of late-onset preeclampsia: a retrospective analysis on 57000 singleton pregnancies in Reunion Island. BMJ Open 10: 036549.

13. Robillard PY, Dekker GA, Boukerrou M, Boumahni B, Hulsey TC, et al. (2020) The urgent need to optimize gestational weight gain in overweight/obese women to lower maternal-fetal moribidities: a retrospective analysis on 59,000 singleton term pregnancies. Archives Women Health Care 3: 1-9.

14. Roberge S, Bujold E, Nicolaides KH (2018) Aspirin for the prevention of preterm and term preeclampsia: systematic review and metaanalysis. Am J Obstet Gynecol 218: 287-293. [crossref]

15. Rolnik DL, Nicolaides KH, Poon LC (2020) Prevention of preeclampsia with aspirin. Am J Obstet Gynecol 21: 30873-30875.

16. Poon LC, Shennan A, Hyett JA, Kapur A, et al. (2019) The International Federation of Gynecology and Obstetrics (FIGO) initiative on pre-eclampsia: A pragmatic guide for first-trimester screening and prevention. Int J Gynaecol Obstet 145: 1-33. Erratum in: Int J Gynaecol Obstet 146: 390-391. [crossref] 
Pierre-Yves Robillard (2020) Risk Factors for Early and Late Onset Preeclampsia in Women without Pathological History: Confirmation of the Paramount Effect of Excessive Maternal Pre-Pregnancy Corpulence on Risk for Late Onset Preeclampsia

17. Wright D, Nicolaides KH (2019) Aspirin delays the development of preeclampsia. Am J Obstet Gynecol 220: 580. [crossref]

18. Saftlas AF, Levine RJ, Klebanoff MA, Martz KL, Ewell MG, et al. (2003) Abortion, changed paternity, and risk of preeclampsia in nulliparous women. Am J Epidemiol 157: 1108-1114. [crossref]

19. Robillard PY, Dekker GA, Hulsey TC (1999) Revisiting the epidemiological standard of preeclampsia: primigravidity or primipaternity? Eur J Obstet Gynecol Reprod Biol 84: 37-41. [crossref]
20. Dekker GA, Robillard PY (2005) Preeclampsia: a couple's disease with maternal and fetal manifestations. Curr Pharm Des 11: 699-710. [crossref]

21. Dekker GA (2014) Pre-eclampsia - A disease of an individual couple. Pregnancy Hypertens 4: 242-243.

22. Dekker G, Robillard PY, Roberts C (2011) The etiology of preeclampsia: the role of the father. J Reprod Immunol 89: 126-132. [crossref]

\section{Citation:}

Pierre-Yves Robillard (2020) Risk Factors for Early and Late Onset Preeclampsia in Women without Pathological History: Confirmation of the Paramount Effect of Excessive Maternal Pre-Pregnancy Corpulence on Risk for Late Onset Preeclampsia. Integr Gyn Obstet J Volume 3(3): 1-7. 